\title{
A QUESTÃO DO TEMA GERADOR EM PAULO FREIRE: PRÁTICAS E EXPERIMENTAÇÕES EM TRACUATEUA-PA
}

\author{
Marcio Fernando Duarte Pinheiro ${ }^{1}$ \\ José Bittencourt da Silva ${ }^{2}$
}

\begin{abstract}
RESUMO
Objetiva-se com este texto expor e analisar a implementação prática das ideias de Paulo Freire no âmbito da Educação de Jovens e Adultos no município de Tracuateua, estado do Pará. As bases teóricas e práticas da educação que este intelectual apresentou foram tomadas como referência nas escolas do município de 2009-2015, ainda que ressignificadas e ajustadas à realidade do lugar. A partir de levantamento documental e entrevistas com técnicos Pedagógicos da Secretaria Municipal de Educação (SEMED), chegou-se à conclusão de que as ideias de Paulo Freire são essenciais para o percurso formativo dos/as educandos/as de Tracuateua. Por isso, os agentes educacionais locais vêm resistindo às pressões no cenário político atual brasileiro buscado manter o trabalho pedagógico alicerçado na escuta e dialogicidade tão caros ao paradigma freiriano de educação.
\end{abstract}

Palavras-chave: Paulo Freire. Tema Gerador. Educação de Jovens e Adultos.

\section{THE ISSUE OF THEME-GENERATOR IN PAULO FREIRE: PRACTICES AND EXPERIMENTS IN TRACUATEUA-PA}

\begin{abstract}
The objective of this text is to expose and analyze the practical implementation of Paulo Freire's ideas in the scope of Youth and Adult Education in the municipality of Tracuateua, state of Pará. The theoretical and practical bases of education that this intellectual presented were taken as a reference in the schools in the municipality since 2015 , although reframed and adjusted to the reality of the place. Based on a documentary survey and interviews with Pedagogical technicians from the Municipal Education Secretariat (SEMED), it was concluded that Paulo Freire's ideas are essential for the formative path of students in Tracuateua. For this reason, local educational agents have resisted pressures in the current Brazilian political scenario, seeking to maintain the pedagogical work based on listening and dialogicity so dear to the Freirian paradigm of education.
\end{abstract}

Keywords: Paulo Freire. Generator theme. Youth and Adult Education

Data de submissão 15.10 .2020

Data de aprovação 27.01.2021

\section{INTRODUÇÃO}

Com a intenção de refletir sobre a implantação do currículo via Tema Gerador a partir das concepções teóricas e práticas de Paulo Freire, este estudo se inscreve como uma pesquisa bibliográfica ancorada nas leituras de algumas obras de Paulo Feire como marco orientador do

\footnotetext{
${ }^{1}$ Mestre em Currículo e Gestão da Escola Básica- Programa de Pós-Graduação em Currículo e Gestão da Escola Básica (PPEB-UFPA). E-mail: marcioduarte101@ @otmail.com.

2 Pós-Doutorado em Educação pela Faculdade de Educação da Universidade Federal da Bahia (FACED/UFBA, 2016); Doutorado em Ciências Ambientais pela Universidade Federal do Pará (UFPA, 2007); Mestrado em Planejamento do Desenvolvimento pela Universidade Federal do Pará (UFPA, 2003). Atualmente é professor Associado nível III da Universidade Federal do Pará, atuando na graduação (Faculdade de Educação-FAED) e Pós-Graduação (Programa de Pós-Graduação em Currículo e Gestão da Escola Básica-PPEB) no Núcleo de Estudos Transdisciplinares em Educação Básica (NEB). E-mail: osebittencourtsilva@ gmail.com.
} 
currículo por Tema Gerador, bem como do uso de produções que situam essa experiência no município pesquisado, desde uma experiência piloto em 2009 até o retorno em 2015 na Rede Municipal de Educação de Tracuateua.

$\mathrm{Na}$ escuta das vozes dos técnicos pedagógicos que estiveram na Secretaria Municipal de Educação (SEMED), visualizou-se as dificuldades, os avanços e os recuos estratégicos marcados, sobretudo, pela conjuntura política nacional brasileira desses últimos anos.

A questão que se apresenta é saber: de que maneira a percepção se fez presente nas práticas educacionais de jovens e adultos, em particular no processo de implantação do currículo via Tema Gerador em Tracuateua-PA? O ponto de partida para responder a essa indagação reside em reconstruir o caminho iniciado no ano de 2009 por ser ele o marco de referência de um projeto piloto em uma única escola de Tracuateua.

Nessa caminhada, apontamos de que forma ocorreu este tipo de organização curricular, seus pressupostos epistemológicos, os avanços e desafios na materialização desse currículo. Para dar conta da apresentação desse percurso, organizamos o trabalho a partir de uma introdução que apresenta os elementos essenciais que propusemos a refletir. Em seguida, adentramos no item que trata da concepção de Paulo Freire como base teórica e prática para a implementação da EJA no Brasil, no qual apresentamos suas ideias acerca da educação. Por fim, traçamos uma análise do currículo via Tema Gerador implantado em Tracuateua em 20152017. Nas considerações finais, sinalizamos aspectos importantes desse currículo que ora toma lugar central como projeto de educação libertadora, ora é silenciado pela resistência de sujeitos que estão à frente da dinâmica educacional nacional.

A conjuntura política nacional e local, a partir dos anos de 2009, foram fundamentais para os atores educacionais de Tracuateua experimentarem uma organização curricular diferente das que estavam em curso. Essa conjuntura fez surgir um desejo de mudança nos sujeitos que reivindicavam outras pedagogias, com existência e resistência transformadora, a partir de um currículo dialógico e participativo.

\section{A CONCEPÇÃO DE PAULO FREIRE COMO BASE TEÓRICA E PRÁTICA PARA A IMPLEMENTAÇÃO DA EJA NO BRASIL}

As concepções teóricas que embasam a educação em Paulo Freire são resultado de uma construção marcada pelo contexto histórico e fruto das diferentes experiências pelas quais ele passou. Foram estas experiências que o ajudaram a construir conceitos essencialmente necessários à elaboração e consolidação de sua proposta educacional na década de 1960.

Reportamo-nos ao pensamento de Paulo Freire quando ele diz que a educação vigente na época não encorajava o homem a debater as problemáticas do momento. Isso acontecia por falta de embasamento teórico capaz de despertar o gosto pelo conhecimento, invenção e pesquisa.

Diante da transição da sociedade brasileira, Freire se via angustiado e esperava ser ele, o educador que poderia contribuir incitando os sujeitos a reivindicarem mudanças nas condições objetivas de existência. Almejava uma educação diferente daquela que até então existia.

Uma educação crítica capaz de mudar o pensamento, que saísse da transitividade ingênua para uma proposta dialógica crítica. Freire entendia que era necessária uma educação para o protagonismo, capaz de colocar os sujeitos em diálogo permanente com seus pares, pois o sentido da democracia implicava participação, mudança, tomar partido, debater ideias. Nas palavras desse teórico, "uma educação que possibilitasse ao homem a discussão corajosa de sua problemática" (FRERE, 1983, p. 89) permitindo-os ver que o mundo não estava acessível a todos.

Freire (1983) se debruça sobre a alfabetização por ser ela o campo inicial e ao mesmo tempo, o tema da maior relevância social e política no Brasil. O aprendizado deveria encontrar- 
se intimamente associado à tomada de consciência da situação real vivida pelos educandos. Nesse contexto, o educador Paulo Freire preocupado com a situação do analfabetismo e, mais ainda, com a opressão das pessoas, deveriam atuar a serviço da libertação de homens e mulheres, acreditando na sua capacidade de criação e de crítica.

E, assim, na cidade de Angicos em 1962, estado do Rio Grande do Norte, Freire constrói uma proposta de educação de adultos cujo resultado foi a alfabetização de 300 trabalhadores rurais em apenas 45 dias. Uma educação que tinha como base a libertação dos sujeitos oprimidos, capaz de despontar a confiança na pessoa humana e na sua capacidade de educar-se como sujeito histórico e social.

A educação de Freire, visava uma postura proativa, dialogal, horizontal, participante e crítica para todos os sujeitos educacionais envolvidos com a alfabetização de adultos. Uma experiência de educação disseminada em várias partes do país, cujo desejo era ainda maior, com o plano elaborado no governo Goulart em 1964. Esse plano objetivava a implantação de 20 mil Círculos de Cultura em todo o território brasileiro. O Círculo se constituía em um grupo de trabalho cujo interesse seria o debate da linguagem no contexto de uma prática social livre e crítica.

Os educadores do Círculo de Cultura eram chamados de coordenadores e os seus papéis eram dialogar com os alfabetizandos oferecendo-lhes os instrumentos para uma alfabetização além das letras. Essa atitude de diálogo proporcionava de fato uma educação libertadora e não simplesmente a domesticação dos sujeitos, visto que o diálogo é uma relação de ida e volta, de intertrocas, ou seja, uma relação de dois sujeitos interlocutores.

Devemos reforçar no âmbito da proposta de Freire, a prática libertadora de educação. Esta se corporifica a partir do processo de construção de conhecimento, diferentemente da concepção bancária ou tradicional, a qual prioriza a transmissão de conteúdo, ora pelo professor, ora pelo aluno. A prática libertadora de educação se faz pelo diálogo crítico, na troca de experiências. Um processo que escapa à polaridade professor/aluno, visto que se ramifica pelo diálogo, pois ambos têm muito a ensinar e muito o que aprender em uma concepção dialética de conhecimento.

Freire (1983) informa que com menos de seis meses os resultados do seu trabalho de alfabetização eram surpreendentes. Os sujeitos não alfabetizados começaram a demostrar a tomada de consciência, reconhecendo-se não apenas sujeitos no mundo, sem propósito, mas sentindo-se parte dele.

É importante destacar que a prática pedagógica de Paulo Freire, revela o respeito à liberdade dos educandos que nunca são chamados de analfabetos, mas de alfabetizandos. $\mathrm{O}$ fato de chamá-los desta forma evidencia o caráter processual em que ocorre a tomada de consciência, cujo desejo se reveste de esperança de que eles possam sair de sua condição de não alfabetizados para sujeitos alfabetizados, leitores das palavras e do mundo.

A educação como uma prática libertadora mostra-se mais democrática do que o ensino tradicional. Nessa perspectiva, o papel do professor e do aluno são colocados em discussão, visto que o professor não é o detentor do conhecimento e, tampouco, se julga transmissor daquilo que julga saber aos alunos. Estes não são considerados apenas assimiladores de conteúdos de forma passiva e receptiva, no qual o conhecimento em nada contribui para/na construção de um sujeito crítico.

Nesse sentido, a educação em uma perspectiva libertadora considera tanto professores quanto alunos sujeitos protagonistas do processo de ensino/aprendizagem. Considera-os como sujeitos cognoscentes da realidade em uma prática emancipatória, ainda que, o conhecimento se apresente de forma diferenciada.

Com isso, o conhecimento pode ser produzido de diferentes formas, seja por meio dos saberes, das experiências historicamente acumuladas, das histórias de vida. $\mathrm{O}$ fato é que a Pedagogia Libertadora, não cabe apenas nos espaços tradicionais de educação chamados 
escolas, ela viabiliza ações que vão possibilitar uma reflexão em uma perspectiva de mudança na sociedade como um todo. Assim, pensar a educação não restringindo-a ao sentido meramente pedagógico, mas também como "um ato político!" (FREIRE, 1986, p. 113).

A alfabetização abre os trabalhos do Círculo de Cultura, e é também o início da conscientização. Ao educador cabe registrar fielmente o vocabulário dos alfabetizandos, selecionar algumas palavras básicas que aparecem com frequência no seu universo vocabular, garantindo que estas sejam relevantes e carregadas de sentido e, sobretudo, que apresentem complexidade fonêmica.

Freire (1983) anuncia as fases de estruturação de sua proposta de educação apresentando cinco passos:

1 - Levantamento do universo vocabular dos grupos com quem se trabalha;

2 - Escolha das palavras selecionadas do universo vocabular pesquisado, a partir de alguns critérios, (riqueza fonêmica, dificuldades fonéticas e teor pragmático da palavra);

3 - Criação de situações existenciais típicas do grupo com quem vai se trabalhar;

4 - Elaboração de fichas roteiros que auxiliem os coordenadores de debate no seu trabalho, estas vão servir apenas como subsídios para os mesmos;

5 - Feitura de fichas com a decomposição das famílias fonêmicas correspondentes aos vocábulos geradores.

É interessante destacar algumas palavras geradoras dos Círculos de Cultura que Freire acompanhou nessa sua experiência, como: favela, chuva, arado, terreno, comida, batuque, poço, bicicleta, trabalho, tijolo, riqueza.

Fazemos menção à primeira palavra geradora pesquisada e aplicada no Estado do Rio de Janeiro, a palavra FAVELA, quando da organização do Círculo de Cultura. Naquela ocasião, o uso de fotografia ampliava os debates, ao passo que faziam emergir os problemas de habitação, alimentação, vestuário, saúde e educação.

Os participantes descobriram a favela como situação problemática, percebendo como ela se formava enquanto texto/contexto. Outras experimentações foram evidenciadas, por exemplo, o grupo de alfabetizandos começaram a criar palavras com as combinações a sua disposição.

Essa experiência de educação de Freire nos mostra que a alfabetização e a conscientização jamais se separam. É possível ler as palavras e ler o mundo concomitantemente. No entanto, o referido autor, alerta que o maior desafio reside em fazer os educandos se perceberem como sujeitos ou não do processo educativo.

A tomada de consciência possibilita abrir os olhos para aquilo que julgam "normal", "natural", desnaturalizando as condições de opressão, de pobreza, de fome, de exploração, de analfabetismo. Embora interrompido pela ditadura militar, observa-se que a proposta pedagógica de Paulo Freire para a educação de Jovens e Adultos é aplicável até hoje em nossa educação, sofrendo reinvenções e reelaborações.

Quanto ao problema de analfabetismo, verifica-se que o perfil descompromissado da educação escolar com as classes trabalhadoras questionado por Paulo Freire na década de 1960, ainda prevalece nos dias atuais.

Podemos dizer que os militares impediram, em grande medida, a concretização do que ficou conhecido como proposta de Alfabetização de Adultos e imprimiram uma pedagogia tecnicista que respondia às necessidades do processo de internacionalização da economia brasileira na década de 1960 (FREIRE, 1986). No entanto, as lutas pela redemocratização do país no final da década de 1970, trouxeram as propostas pedagógicas de Paulo Freire para os sistemas educativos atuais, cujo desejo é o de uma educação não fragmentada pelas artimanhas do autoritarismo.

Movente como os sonhos de Freire, Tracuateua a partir dos anos 90 veio experimentando a pedagogia libertadora em seus currículos escolares para a Educação de 
Jovens e Adultos. Com um projeto pedagógico piloto inovador, mostrou-se capaz de atender os educandos desenvolvendo sua criticidade.

Permanentemente reinventado e reelaborado, o projeto via Tema Gerador de base freiriano, longe de ser perfeito, mostra os avanços e suas dificuldades ao longo dos anos de implementação. $\mathrm{O}$ destaque que queremos dar a essa experiência, reside na perspicácia de alguns protagonistas, agentes do processo educativo que estiveram como condutores em seus contextos, seja a escola, o sistema de ensino ou a comunidade.

\section{CURRÍCULO VIA TEMA GERADOR E A EXPERIÊNCIA DO MUNICÍPIO DE TRACUATEUA-PA}

Diante das escutas realizadas com os técnicos educacionais da Secretaria Municipal de Educação, sempre houve preocupação acerca da educação municipal e os seus rumos. Uma delas, diz respeito à organização pedagógica das escolas em seus níveis e modalidades de ensino. Percebeu-se na polissemia das vozes desses sujeitos um desejo materializado em ato, o de buscar outras perspectivas de currículos que não se distanciassem da realidade dos seus educandos e que, sobretudo, primasse pela dialogicidade e pela construção coletiva. Ressaltamos que nos últimos anos, o trabalho pedagógico mostra-se promissor desse ato coletivo, do fazer com o outro, envolvendo diferentes sujeitos da escola, como os professores, alunos, gestores, técnicos pedagógicos, profissionais de apoio e comunidade

Considera-se na experiência relatada sobre o projeto via Tema Gerador, que todos os sujeitos são importantes, agindo como construtores da educação de Tracuateua. Nas vozes dos técnicos pedagógicos, as resistências por parte de alguns grupos eram presentes, mas o que se coloca é antes, o esforço para materializar uma proposta que necessitava, em sua essência, do outro como sujeito de voz.

Foi nessa tentativa, diante da grande evasão dos alunos da Educação de Jovens e Adultos, que Tracuateua experimentou em 2009 outra organização curricular, o currículo via Tema Gerador. No que compete a essa evasão escolar, podemos visualizar e compreender melhor analisando a Tabela a seguir, que traz um levantamento dos últimos 20 anos.

Tabela 1- Demonstrativo da demanda escolar na rede municipal de Tracuateua desde a sua implantação em 1997

\begin{tabular}{|c|c|c|c|c|c|c|c|c|}
\hline & MUNICI & IO DE TR & ICUATE & & $\begin{array}{r}\mathbf{N}^{0} \text { DE A } \\
\text { DA Z } \\
\text { URB }\end{array}$ & $\begin{array}{l}\text { UNOS } \\
\text { NA }\end{array}$ & $\begin{array}{r}N^{0} \text { DE A } \\
\text { DA ZONA }\end{array}$ & $\begin{array}{l}\text { LUNOS } \\
\text { RURAL }\end{array}$ \\
\hline ANO & & DE ESCOL & & $\begin{array}{c}\mathrm{N}^{\circ} \mathrm{DE} \\
\text { ALUNOS }\end{array}$ & EJ & & EJ & \\
\hline & TOTAL & \begin{tabular}{|c|} 
ZONA \\
URBANA
\end{tabular} & $\begin{array}{l}\text { ZONA } \\
\text { RURAL }\end{array}$ & EJA & $\begin{array}{l}\text { SÉRIES } \\
\text { INICIAIS }\end{array}$ & $\begin{array}{l}\text { SÉRIES } \\
\text { FINAIS }\end{array}$ & $\begin{array}{l}\text { SÉRIES } \\
\text { INICIAIS }\end{array}$ & $\begin{array}{l}\text { SÉRIES } \\
\text { FINAIS }\end{array}$ \\
\hline 1997 & 49 & 1 & 48 & 0 & 0 & 0 & 0 & 0 \\
\hline 1998 & 55 & 1 & 54 & 166 & 0 & 166 & 0 & 0 \\
\hline 1999 & 59 & 2 & 57 & 334 & 0 & 334 & 0 & 0 \\
\hline 2000 & 59 & 2 & 57 & 434 & 0 & 186 & 0 & 248 \\
\hline 2001 & 59 & 2 & 57 & 893 & 32 & 191 & 427 & 243 \\
\hline 2002 & 58 & 2 & 56 & 1012 & 36 & 194 & 479 & 303 \\
\hline 2003 & 54 & 2 & 52 & 725 & 31 & 96 & 407 & 191 \\
\hline 2004 & 54 & 2 & 52 & 602 & 42 & 181 & 260 & 119 \\
\hline 2005 & 61 & 4 & 57 & 565 & 0 & 361 & 0 & 204 \\
\hline
\end{tabular}




\begin{tabular}{|c|c|c|c|c|c|c|c|c|}
\hline 2006 & 64 & 5 & 59 & 466 & 0 & 302 & 0 & 164 \\
\hline 2007 & 56 & 4 & 52 & 472 & 0 & 338 & 0 & 134 \\
\hline 2008 & 67 & 5 & 62 & 461 & 21 & 255 & 23 & 162 \\
\hline 2009 & 59 & 5 & 54 & 376 & 22 & 191 & 21 & 142 \\
\hline 2010 & 60 & 5 & 55 & 531 & 19 & 217 & 116 & 179 \\
\hline 2011 & 58 & 5 & 53 & 533 & 23 & 198 & 104 & 208 \\
\hline 2012 & 59 & 5 & 54 & 517 & 34 & 169 & 108 & 206 \\
\hline 2013 & 58 & 5 & 53 & 668 & 38 & 182 & 209 & 239 \\
\hline 2014 & 60 & 5 & 55 & 558 & 31 & 163 & 148 & 216 \\
\hline 2015 & 59 & 5 & 54 & 329 & 23 & 139 & 30 & 137 \\
\hline 2016 & 59 & 5 & 54 & 241 & 19 & 77 & 45 & 100 \\
\hline 2017 & 59 & 5 & 54 & 188 & 15 & 101 & 30 & 42 \\
\hline
\end{tabular}

Os dados mostram que as matrículas na Educação de Jovens e Adultos tem diminuído drasticamente nos últimos anos.

Isso nos leva a refletir sobre o futuro dessa modalidade de educação em Tracuateua forjando um cenário de perguntas: Quais os motivos que levam os alunos a evadirem da escola? O que o município tem feito para evitar a evasão escolar?

Longe de ter respostas para essas questões, queremos evidenciar os caminhos percorridos em aproximadamente uma década de educação municipal. Talvez as respostas estejam imbricadas na conjuntura política, cujo cenário nem sempre esteve a favor da educação libertadora.

Portanto, iniciemos falando da ocasião em que o projeto via Tema Gerador foi implantado em uma escola piloto de Tracuateua. Na ocasião em que se colocou em prática o currículo por Tema Gerador em 2009, havia apenas três escolas dentro do quantitativo de 59 de toda a Rede Municipal que ofertavam essa modalidade. E foi em uma delas que o projeto foi implantado sob a orientação e assessoria de professores da Universidade Federal do Pará UFPA. Em um texto produzido por estes professores (NEVES; MARCIEL, 2009) que encontrase disponível em endereço eletrônico ${ }^{3}$, eles descrevem como se deu essa primeira experiência, os seus desdobramentos e a organização da proposta. Dentre os objetivos almejados estava o desenvolvimento de uma formação comprometida com a vida das pessoas e com a história do município de forma que o resultado fosse a transformação. Os formadores/autores chamam esta experiência de teia do conhecimento.

A teia direcionava o trabalho educativo, tomando como ponto de partida a realidade dos alunos, pois só assim eles estariam preparados para lidarem com as problemáticas sociais. A construção da teia se fazia via processo formativo diante das falas significativas. Estavam em cenas educadores, educadoras e a escolarização dos Jovens e Adultos. Para fazer a formação dos educadores era preciso se colocar no contexto onde atuavam para transformar aquela realidade.

Diante disso, a equipe técnica pedagógica da escola formada pelo diretor e coordenadores pedagógicos tinham um papel central enquanto articuladores e orientadores da proposta. Todos eram convidados a assumirem o lugar de formadores nos seus contextos. Empoderados das discussões, os polos eram frutificados com debates, discussões e proposições. Essa produção coletiva revestia-se pela importância dada pelos sujeitos à essa construção.

\footnotetext{
${ }^{3}$ https://pt.scribd.com/document/107190461/os-temas-geradores-na-formacao-de-educadoras-e-educadores-e-naalfabetizacao-de-jovens-e-adultoS
} 
Russo (2011, p. 504) destaca o trabalho do diretor e coordenador pedagógico, responsabilizando-os pela:

[...] mediação para que o ensino se realize com o máximo de eficácia e de eficiência possível em cada caso concreto, isto é, com os recursos humanos, materiais e financeiros disponíveis em cada escola. $\mathrm{O}$ trabalho desses agentes tem efeito direto no processo de ensino aprendizagem porque tem como finalidade criar condições favoráveis à sua realização, à preparação adequada dos docentes e dos discentes, à sua participação no processo ou, ainda, à correção de desvios que possam contribuir para o fracasso do processo.

Assim, acreditar que eles poderiam empoderar-se para construir condições favoráveis ao ensino dos alunos. Para os formadores da UFPA, o conhecimento não seria apenas uma doação daquilo que julgavam possuir, mas uma ferramenta importante na construção da compreensão da realidade e na conquista da escolarização de Jovens e Adultos.

Os professores que lançaram essa proposta no município se reportam a teia enquanto perspectiva que possibilitaria desnaturalizar as situações, no qual os sujeitos estão em movimento para alcançar a autonomia. Uma experiência que se traduz no trabalho coletivo entre educadores, educadoras, rede de educação e apoio pedagógico.

As etapas da construção e escolha do tema gerador nascia da pesquisa da realidade sobre a história e o fazer dos sujeitos do processo, neste caso, os alunos da EJA da escola Raimundo Pinheiro de $\mathrm{Melo}^{4}$. Os autores descrevem que durante o processo de formação em 2009 percorreram dois caminhos, conforme mostra a narrativa a seguir:

O primeiro foi fazer a pesquisa a partir das histórias de vida dos educandos e educandas, alunos da Escola RPM, num processo de escuta, diálogo e reflexão. Este material foi organizado em Teia de conhecimento tanto a formação dos/as educadores/as quanto para organização da estrutura curricular da EJA. Para este levantamento, os sujeitos da EJA, coordenados pelos/as educadores/as, registram em todas as turmas, através do desenho, o que era significativo em sua história de vida. Depois socializaram as suas histórias. Neste processo, os/as educadores/as buscaram registrar o que havia de comum nas histórias de educandos e educandas e, a partir daí, encontramos o tema gerador e os eixos temáticos que possibilitarão a reflexão sobre o contexto em que os sujeitos da EJA vivem e no qual se inserem também os/as educadores/as dessa modalidade de ensino. [...].

O segundo caminho articulado ao primeiro, foi organizado no sentido de que os/as educadores/as possam desenvolver pesquisa em suas turmas, utilizando-se da metodologia de projetos. Cabe ressaltar que um projeto não é apenas um plano de trabalho ou um conjunto de atividades bem organizadas. Há muito mais na essência de um bom projeto. Esta metodologia pretende possibilitar elementos teórico/ metodológicos aos/as educadores/as, ou seja, a forma que procedemos no levantamento dos Temas Geradores e na organização da programação deve servir de referência para suas práticas em suas turmas de escolarização. Não posso investigar o pensar dos outros, referido ao mundo, se não penso. Mas não penso autenticamente se os outros também não pensam. Simplesmente não posso pensar pelos outros nem para os outros, nem sem os outros (NEVES; MARCIEL, 2009. p. 4).

Sobre as escolhas dos Temas Geradores, Neves e Marciel (2009) indicam que eles partiam das necessidades e não das vontades pessoais dos sujeitos do processo. Por isso, as necessidades compunham um patamar que precisavam ser entendidas teoricamente, para que o planejamento e o processo de tomada de decisão (escolhas) fossem coerentes com a realidade. As orientações eram de que a escolha do tema para trabalhar o bimestre fossem resultado da vontade do coletivo, tomando como referência os alunos, a comunidade e a sociedade.

\footnotetext{
${ }^{4}$ Escola da rede municipal de educação, localizada no Bairro Água-Fria. Naquele momento, atendia crianças da Educação Infantil, do ensino fundamental e da Educação de Jovens e Adultos.
} 
Este foi um recorte de como se deu essa experiência em 2009, uma vez que pouco foram os achados para nos permitir reconstruir o início de uma trajetória que pensamos ser a mais indicada para o trabalho com a Educação de Jovens e Adultos. Uma experiência que gerou muitas expectativas por parte dos professores, pois eles não estavam sozinhos, mas podiam contar com a parceria de outras instituições, de outros sujeitos, como os gestores, coordenadores pedagógicos e alunos.

Durante todo o ano de 2009 foram ofertadas formações docentes sobre o que significava trabalhar com os temas geradores. De certa forma, havia o reconhecimento de que a educação necessitava dos sujeitos, professor, aluno, gestor, coordenador.

Um trabalho árduo, mas que potencializava a educação libertadora. As formações constantes direcionadas pela Rede Municipal de Educação e o apoio da gestão escolar colaboraram na caminhada dos professores rumo a autonomia na elaboração e construção das suas práticas.

Houve a redescoberta por parte dos alunos da sua importância e centralidade dentro do processo educativo. Um projeto novo baseado nos princípios da "democracia, da solidariedade e da esperança" (ESTÊVÃO, 2013, p. 24) que foi freado com as mudanças no campo político de Tracuateua a partir das eleições municipais.

Refletimos que a política partidária tem mudado drasticamente os rumos da educação do município. Os discursos ensaiados por quem ocupa os cargos de gestão nas secretarias reside em não continuar os projetos de gestões anteriores, sob a alegação de quererem deixar sua marca, construir outra história. O problema disso, é que a história não pode ser apagada, pois a memória, sobretudo a coletiva, se encarrega de avivar aquilo que muitos querem deixar adormecido.

Em 2015 e 2016 o projeto retorna para a Rede Municipal, dessa vez não apenas para a EJA, mas para todos os níveis e modalidades de educação. Orientado pelos mesmos professores que estiveram em 2009, o currículo via Tema Gerador se dividiu entre os críticos e os adeptos.

Para este início foram realizadas formações intensas e periódicas com a equipe técnica da Secretaria Municipal de Educação. O objetivo dessas formações era aproximar os docentes e técnicos daquilo que seria a base de sua atuação, a epistemologia de Paulo Freire como subsídio teórico e prático na construção de um currículo que tomasse como ponto de partida, o lugar e a história dos sujeitos.

\footnotetext{
Nós partirmos das experiências vividas acreditando que a formação dos professores, a ideia do planejamento ela tem que estar correlacionada ao processo de formação dos professores, onde o próprio texto que a gente trabalha é um texto que discute a categoria da ideia da formação no exercício. Nós trabalhamos com a visão de que o planejamento não pode ser algo estanque. Essa é uma das coisas que a gente pauta. (Professora Joana D’arc, docente da UFPA, comunicação oral, Secretaria Municipal de Educação, 08, fevereiro de 2018).
}

As formações sempre focavam nas diretrizes desse currículo, incitando o diálogo com a realidade dos sujeitos. O diálogo possibilitaria o desenvolvimento de uma consciência crítica e transformadora. O texto de apoio utilizado para aprofundar as discussões teóricas foi uma tese de doutorado de Silva (2004), na qual o autor fundamenta as concepções deste currículo.

O referido autor vai buscar em Freire (1992) e Dussel (2000) as bases epistemológicas de um currículo ético e crítico que parte das falas significativas no processo de problematização da realidade para trabalhar com práticas contextualizadas. Com isso, ele assume a importância do outro no processo de construção da educação. Freire (1987, p. 49) indica o caminho que devemos fazer para chegar a essas falas significativas:

O que temos de fazer, na verdade, é propor ao povo, através de certas contradições básicas, sua situação existencial, concreta, presente, como problema que, por sua vez, 
o desafia e, assim, lhe exige resposta, não só no nível intelectual, mas no nível da ação.

As contradições presentes nas situações existenciais do povo, surgiria mediante a pesquisa sociocultural, a qual revelaria as situações significativas e conflituosas, uma vez que "é na realidade mediatizadora, na consciência que dela tenhamos educadores e povo, que iremos buscar o conteúdo programático da educação (FREIRE, 1987, p. 50).

O conteúdo da educação seria aquele que surge das vozes do povo diante da realidade que vivem. Um conteúdo vivo, dinâmico e em construção. Nesta perspectiva, ele confronta com os modelos anti-dialógicos que chegam sem nenhum questionamento. Freire, educador que defende o caráter dialógico da educação, vem dizer que é pelo diálogo que se chega ao "universo temático do povo ou o conjunto de seus temas geradores" (FREIRE, 1987, p. 50), como explicita a fala da professora Joana quando diz "Nós tínhamos um formato de diálogos com os professores e gestores e eles ficavam responsáveis em realizar as formações com os professores das escolas". (Joana D'arc, docente da UFPA, comunicação oral, Secretaria Municipal de Educação, 08, fevereiro de 2018). O diálogo ocorria entre os sujeitos da escola sempre com a intenção de chegar aos temas de maior relevância para serem trabalhados.

De 2015 a 2016 foram dois anos de debate, estudos e construções com o mesmo grupo que iniciou o projeto em 2009. Novamente, as mudanças no cenário político provocaram (re) laborações no campo curricular das escolas de Tracuateua. Desta vez, os temas geradores se restringem apenas a modalidade da Educação de Jovens e Adultos. A fala de uma coordenadora que esteve responsável pela EJA na Secretaria Municipal de Educação, reflete a preocupação em permanecer com o trabalho que vinha sendo desenvolvido em anos anteriores:

[...] eu não queria que adotassem outro currículo, eu não queria que fosse feito de outra forma, eu queria que dessem continuidade a um trabalho que a gente já tinha construído no decorrer dos anos anteriores, essa era a minha maior preocupação (Esp. Danubia Ribeiro, técnica da SEMED, comunicação oral, Secretaria Municipal de Educação, 05, janeiro de 2018).

Permanecer nessa perspectiva curricular na modalidade de EJA foi um desafio, uma vez que a rotatividade dos professores de um nível para outro ou mesmo a saída deles da função docente tem provocado quebras na dinâmica formativa e prática nas escolas. Há ainda, o fato de que nem todos os professores se alinham bem ao projeto por Tema Gerador, optando em seguir os conteúdos de ensino das matrizes curriculares.

Diante disso, fica explícito que Tracuateua foi audaciosa em buscar construir um projeto coletivo de educação, no qual o foco eram os sujeitos e suas problemáticas. Uma educação para a mudança privilegiando a coparticipação, a dialogicidade, a humanização. Sem deixar de refletir nos desafios encontrados, vemos essa tentativa como uma possibilidade para alcançar graus mais elevados de democracia e autonomia.

\section{CONSIDERAÇÕES FINAIS}

Trazer para o centro da discussão a efetivação de experiências freireanas realizadas em um município da região bragantina não é um exercício fácil de realizar. A implantação do currículo via Tema Gerador não foi tão simples, mas muito promissor. Foi preciso ir ao encontro de vozes que desde o começo foram imprescindíveis na provocação sobre o ato de planejar, de pensar a escola e a educação.

Necessário ainda, foi o encontro com as ideias de Paulo Freire enquanto base epistemológica na materialização de um currículo que considera os sujeitos como verdadeiros autores desse projeto. Fato que verbera o sentido mais autêntico da educação. Uma educação partilhada com os sujeitos que dela se fazem produto e processo. 
As bases epistemológicas que ajudaram na construção desse projeto nas escolas de Tracuateua, tomaram como ponto de partida a concepção de que a escola não pode servir como depósito de conhecimento, mas é preciso senso crítico para enfrentar os problemas da atualidade. Uma educação que problematiza as situações existenciais, tornando as pessoas sujeitos de sua história.

Em diálogo permanente é possível chegar ao conteúdo da educação que emerge das vozes dos sujeitos nos seus lugares de vida e de cultura. Nesses termos, é imperativo para qualquer projeto de EJA o diálogo como prática de liberdade, de autonomia, de mudança, de esperança.

A partir dos pressupostos freireanos, o município de Tracuateua tem buscado nesses anos em que o projeto esteve em vigor, construir uma educação problematizadora que fosse capaz de revelar a identidade dos seus sujeitos, agora vistos como protagonistas de história, da sua própria história. Apesar dos grandes desafios, é possível frisar que os ganhos são evidentes, ainda que não tenham contemplado todos, uma vez que para isso é preciso vontade, responsabilidade e compromisso político associado a uma boa dose de utopia.

\section{REFERÊNCIAS}

BRASIL, Ministério da Educação. INEP. Município- Resultado do Censo Escolar. 2017.

DUSSEL, Henrique. Ética da Libertação na idade da globalização e da exclusão.

Petrópolis: Vozes, 2000.

ESTÊBÃO, Carlos Vilar. A qualidade da educação: suas implicações na política e na gestão pedagógica. RBPAE - v.29, n. 1, p.15-26, 2013. Disponível em:

http://seer.ufrgs.br/index.php/rbpae/article/view/42818. Acesso em: 12 ago. 2020.

FREIRE, Paulo. Educação como prática da liberdade. $14^{\mathrm{a}}$ ed. Rio de Janeiro: Paz e terra, 1983.

FREIRE; Paulo; SHOR; Ira. Medo e Ousadia: o cotidiano do professor. Trad. LOPES, Adriana. Rio de Janeiro: Paz e Terra, 1986.

FREIRE, Paulo. Pedagogia do oprimido. 17ª ed. Rio de Janeiro: Paz e Terra, 1987.

FREIRE, Paulo. Pedagogia da Esperança. Rio de Janeiro: Paz e Terra, 1992.

NEVES, Joana Dárc; MARCIEL, Rogerio. Os temas geradores na formação de educadoras e educadores na escolarização de jovens e adultos. Disponível em: http://pt.scribd.com/document/107190461/os-temas-geradores-na-formacao-de-educadoras-eeducadores-e-na-alfabetizacao-de-jovens-e-adultoS. Acesso em: 19 nov. 2019.

RUSSO, Miguel Henrique. Trabalho e administração da escola: desenvolvimento e apropriação do sentido que assumem no processo de produção pedagógica. RBPAE - v.27, n.3, p. 361-588, set./dez. 2011. Disponível em: http://seer.ufrgs.br/rbpae/article/view/26416. Acesso em: 18 nov. 2019.

SILVA, Antônio Fernando Gouvêa da. Construção do currículo na Perspectiva Popular crítica: das falas significativas às práticas contextualizadas. Tese (Doutorado em Educação) 
Programa de pós-graduação em educação: currículo. Pontifícia Universidade Católica de São Paulo. São Paulo, 2004. Disponível em:

http://websmed.portoalegre.rs.gov.br/escolas/quintana/tese_gouvea.pdf. Acesso em: 12 ago. 2020. 